\title{
El contacto y la comunicación en la pandemia*
}

[Artículos]

\author{
J. Ignacio 'Iñaki' Chaves $G .^{* *}$
}

Recibido: 26/11/202O

Aprobado: 16/12/2020

Citar como:

Chaves, J. I. (2021). El contacto y la comunicación en la pandemia. Análisis, 53(98).

https://doi.org/10.15332/21459169.6313

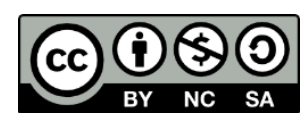

\section{Resumen}

El ser humano es un animal social y físico que se construye desde y por el cuerpo. Es porque los demás son y lo hacen ser, y se "alimenta” del contacto con sus congéneres. Parte de ese "contacto" es la comunicación por la que establece relaciones sociales con otras personas.

La sociabilidad es un tema de contacto y de comunicación, o viceversa, porque por la comunicación mantenemos el contacto con los otros y el contacto es una manera de comunicarnos. ¿Cómo han sido la comunicación y el contacto durante la pandemia? Parece que hemos entrado en un museo virtual en el que nuestros acercamientos se han visto constreñidos a las conexiones a través de las pantallas.

\footnotetext{
* Artículo de reflexión.

** Doctor en Comunicación y Ciencias Sociales. Miembro del grupo de investigación Laboratorio de Comunicación y Cultura (COMandalucía), en la Universidad de Málaga (UMA); de la Asociación Española de Investigación de la Comunicación (AE-IC); de la Asociación Latinoamericana de Investigadores de la Comunicación (ALAIC), y de la Federación Internacional de Prensa (IFJ-FIP). Correo electrónico: ichaves61@gmail.com. ORCID: http://orcid.org/0000-0002-7820-1051
} 
Dado que estamos viviendo el encierro provocado por la pandemia de la covid-19 como si fuera una película (Chaves, 2020, 14 de junio), es pertinente reflexionar alrededor de la comunicación y el contacto en estos tiempos inciertos. Para ello, se considera oportuno hacerlo a partir de algunas pinturas representativas y las metáforas de la vida que contienen. Una manera de asumir las dificultades como un paseo virtual por una pinacoteca, sin una ruta predeterminada pero con la pretensión de contar sobre cómo están siendo las relaciones comunicacionales, qué lugar ocupan y cómo se han visto afectadas. El futuro dependerá en gran parte de cómo nos enfrentemos comunicacional y afectivamente a la "nueva" situación surgida de esta metamorfosis social que estamos sufriendo.

Palabras clave: contacto, comunicación, pandemia, pinacoteca.

\section{Contact and communication in the pandemic}

\section{Abstract}

The human being is a social and physical animal that is built from and by the body. It is because others are and make him be; and it "feeds" on contact with its fellows. Part of that "contact" is the communication by which he establishes social relations with other people.

Sociability is a matter of contact and communication, or vice versa, because through communication we maintain contact with others and contact is a way of communicating. How have communication and contact been during the pandemic? It seems that we have entered a virtual museum in which our approaches have been limited to connections through the screens.

Given that we are living the lockdown caused by the COVID-19 pandemic as if it were a movie (Chaves, 2020, June 14), it is pertinent to reflect on communication and contact in these uncertain times. To this end, it is considered appropriate to do so on the basis of some representative paintings and the metaphors of life they comprise. A way of assuming the 
difficulties as a virtual walk through an art gallery, without a predetermined route but with the pretense of knowing how the communicational relationships are being, what place they occupy and how they have been affected. The future will depend to a large extent on how we face the "new" situation that has arisen from this social metamorphosis we are experiencing, both communicatively and affectively.

Keywords: contact, communication, pandemic, picture gallery.

\section{Contato e comunicação na pandemia}

\section{Resumo}

O ser humano é um animal social e físico que é construído desde e pelo corpo. É porque os outros são e se fazem ser, e ele "se alimenta" do contato com seu semelhante ser humano. Parte desse "contato" é a comunicação pela qual se estabelece relações sociais com outras pessoas.

A sociabilidade é uma questão de contato e comunicação, ou vice-versa, pois pela comunicação mantemos contato com outras pessoas e o contato é uma forma de nós nos comunicarmos. Como tem sido a comunicação e o contato durante a pandemia? Parece que entramos num museu virtual no qual nossas abordagens foram restritas a conexões por meio das telas.

Dado que estamos vivendo o confinamento causado pela pandemia da covid-19 como se fosse um filme (Chaves, 2020, 14 de junho), é pertinente refletir sobre comunicação e contato nesses tempos incertos. Para isso, é considerado apropriado fazê-lo a partir de algumas pinturas representativas e das metáforas da vida que contêm. Uma maneira de assumir as dificuldades como um passeio virtual por uma pinacoteca, sem um caminho predeterminado, mas com a intenção de contar como estão as relações comunicacionais, que lugar ocupam e como foram afetadas. O futuro dependerá, em grande parte, de como lidamos 
comunicativa e emocionalmente com a "nova" situação decorrente dessa metamorfose social que estamos passando.

Palavras-chave: contato, comunicação, pandemia, pinacoteca.

\section{Introducción}

Desde que nacemos, buscamos el relacionamiento con los demás. El bebé necesita del calor materno tras llegar al mundo. La mamá se comunica con su recién nacida por la piel. La piel es el medio de comunicación de los humanos con sus seres cercanos. Después, las miradas, los sonidos, los olores y el gusto al amamantar. Todo un proceso comunicacional intergeneracional. Ahí da comienzo todo y sigue a lo largo de una existencia en la que la comunicación, por el medio que sea, mantiene las vinculaciones humanas.

Durante la pandemia provocada por el coronavirus, los cuerpos han sido relegados a un encierro domiciliario que nos ha privado de ese contacto y de la comunicación directa. Lo físico ha pasado a segundo plano y la presencia ha sido sustituida por la "virtualidad". Nos hemos tenido que encontrar y comunicar a través de las pantallas.

Este texto nos acerca a la situación vivida en un paseo virtual por un museo creado ad hoc para la ocasión y en el que se relacionan tres de las situaciones de contacto comunicacional más cotidianas - un apretón de manos, un abrazo y un beso- con tres imágenes que las representan para indicar cómo ha sido esa comunicación. Más adelante, se muestran tres pinturas icónicas como metáfora de unas conclusiones sobre la situación comunicacional sufrida durante la pandemia. Para terminar, otra famosa pintura sirve a modo de cierre de un recorrido virtual en el que se ha reflexionado metafóricamente sobre la comunicación y el contacto condicionados por el coronavirus y se arriesga un posible panorama sobre 
lo que vendrá en cuanto a los dos sujetos del título y qué papel habrán de jugar la academia y sus profesionales.

\section{El contacto comunicacional}

El contacto y la comunicación que nos alimentan como seres humanos han sido marginadas, y nuestras relaciones mentales y físicas han sido golpeadas bruscamente por un virus que lo ha trastocado todo. La pandemia ha roto el hilo conductor de esa comunicación humana, el mensaje ha quedado cortado y llega a su destinatario por una imagen, a través de una pantalla en la que se puede apreciar una mirada entre triste y asombrada, que dice a su mirador o miradora que no toca para no herir, pero que hay heridas mutuas que no sanan las miradas, ni el deseo ni las palabras.

Comunicación significa "compartir con" y eso no se da cuando las relaciones se establecen a través de las pantallas. Aunque se haya potenciado el uso de las redes virtuales, no sociales porque precisamente lo social requiere de la presencia, se ha perdido en gran parte el contacto y se han puesto límites físicos a la comunicación:

Es el contraste entre el modelo de información vertical modernizador impulsado por el poder económico-político y el modelo comunicacional participativo presente en los movimientos sociales, en auténticas redes sociales hechas piel con piel, lejos de las virtuales, definidas hoy desde Internet; útiles y necesarias, pero donde el valor de lo humano se distancia en la soledad de la máquina y la privacidad del domicilio, y donde el manejo de las nuevas herramientas sigue estando en manos de una minoría. (Chaparro, 2015, p. 94)

Un simple (o no tanto) virus ha suspendido, de manera inesperada, las caricias; ha interrumpido los abrazos, ha cortocircuitado la comunicación, 
ha aislado los cuerpos y los ha envuelto en tapabocas y ropa antifluidos. Ya no hay comunicación en redes realmente sociales, mientras se comparten lugares. Ahora sí que las comunicaciones y las relaciones han devenido en algo netamente virtual.

Tampoco hay espacio para que las pieles se toquen, se rocen, se junten, se fundan en una sola. Y no digamos algo más que piel con piel, no piensen en el sexo. Quien lo haga queda relegado a una condena de quince días de convivencia monacal que asegure que el periodo de incubación anuló el contagio. Y, después, el contacto será cohibido, sospechoso, transgresor, casi ilegal. La comunicación estará rota por el temor, la duda y la incomprensión.

La incertidumbre del actual contexto social nos ha privado de la reunión, a veces por mandato de quienes nos gobiernan y otras por temor al contagio; nos hemos visto obligados a la distancia física y social. Ahora son los pixeles los que nos sirven como "piel" de nuestras interlocutoras. Ya no podemos contar con la certeza del cuerpo, pues nos han privado de la reunión y nos ha asaltado la incertidumbre del “¿hasta cuándo?”.

\section{La comunicación como un museo}

En estos tiempos nos vemos como si visitáramos las salas de una pinacoteca; un museo virtual por el que navegamos de reunión en reunión, de clase en clase, de sala en sala, para comunicarnos y contactar con otras personas. Tomamos fotos de las pantallas para inmortalizar el "cuadro" que se nos presenta, también para justificar la tarea llevada a cabo y que respaldará la actividad desarrollada. En este caso, la sala más visitada, y por tanto los lienzos más retratados, son por lo general, en el ámbito educativo, las y los estudiantes que nos siguen (si disponen de la tecnología para ello), como si fuéramos el guía del museo. Toman notas de 
nuestras explicaciones acerca de teorías y metodologías, a la par que fotografían la diapositiva de nuestra presentación virtual como si fuera una de las obras de arte del recorrido. También hacemos capturas de pantalla, en otra sala de la visita, de los rostros de compañeras y compañeros que participan en los ya cansinos e innumerables webinars y, en una tercera estancia del itinerario, retratamos los rostros de nuestras familias que "compran la entrada" para poder asistir a esa invitación por videoconferencia como el recurso que les queda para el encuentro. Todas y todos visitamos asombrados los diferentes espacios de reunión a través de las múltiples pantallas sin asumir del todo una situación que, pese al mayoritario uso de las nuevas herramientas tecnológicas, nos ha pillado de sorpresa y, en muchos casos, sin la preparación adecuada para enfrentarla. Estamos comprobando, en vivo y en directo y sin anestesia, si la comunicación virtual, como la educación, es una comunicación "sin distancias" (García, 2007).

Todo se ha convertido en una pinacoteca virtual. En una muestra aleatoria, por lo incierto de la conectividad, y supuesta, porque los rostros han sido sustituidos por íconos o siglas que "representan" y nombran a nuestros interlocutores, que hemos de presumir que están del otro lado. La otrora comunicación cercana y cierta se ha convertido, ahora al albur de los avatares tecnológicos, en algo lejano e incierto que puede ser interrumpido por los designios de unas plataformas de conexión no siempre fiables. Los antiguos contactos, los añorados acercamientos físicos se han transformado en inalcanzables pinturas hechas de pixeles.

Ahora los museos son salones virtuales en los que nos encontramos con los cuadros que nos reflejan las pantallas y que tenemos que dar por ciertos y verdaderos, pese a transcurrir frente a nuestros ojos como una película de política ficción: 
[...] una sucesión de imágenes que nunca hubiéramos imaginado y que van grabando en nuestra memoria, fotograma a fotograma, unos hechos inesperados y sorprendentes que se nos dan a conocer casi que virtualmente y nos llevan de la incredulidad al temor y a la incertidumbre. (Chaves, 2020, 14 de junio)

\section{Las nuevas pinturas del museo}

Podemos ejemplificar la nueva comunicación y los nuevos contactos en tres imágenes de otros tantos momentos que significaban mucho en las relaciones humanas. Tres acercamientos físicos sencillos que comunicaban socialmente mucho y que ahora son como pinturas prohibidas, como obras censuradas por una inquisición medieval que impone restricciones a nuestras relaciones vitales, supuestamente para protegernos una vida que ya no nos dejan vivir como antes.

Esas tres situaciones se condensan en tres simples cuadros que, en estos tiempos, han podido ser retirados de las salas del museo y han sido elegidos para engrosar el catálogo de piezas almacenadas en el sótano de lo reprobado, donde se aloja lo condenado al olvido. Así será hasta nueva orden o hasta que un nuevo sistema político lo salve del ostracismo social y los recupere como narraciones gráficas contra el olvido y por la memoria en países que suelen tener pocas ganas de recordar (Colorado, 2019). Uno es el protocolario y firme apretón de manos que ahora ha sido rebajado a una simple imagen que lo muestra; un recuerdo en la memoria de aquel momento que sellaba un encuentro amistoso, que daba fe de la "firma" del acuerdo conseguido o que constataba una despedida por un período de tiempo sin concretar (figura 1). 
Figura 1. Primer cuadro, Apretón de manos

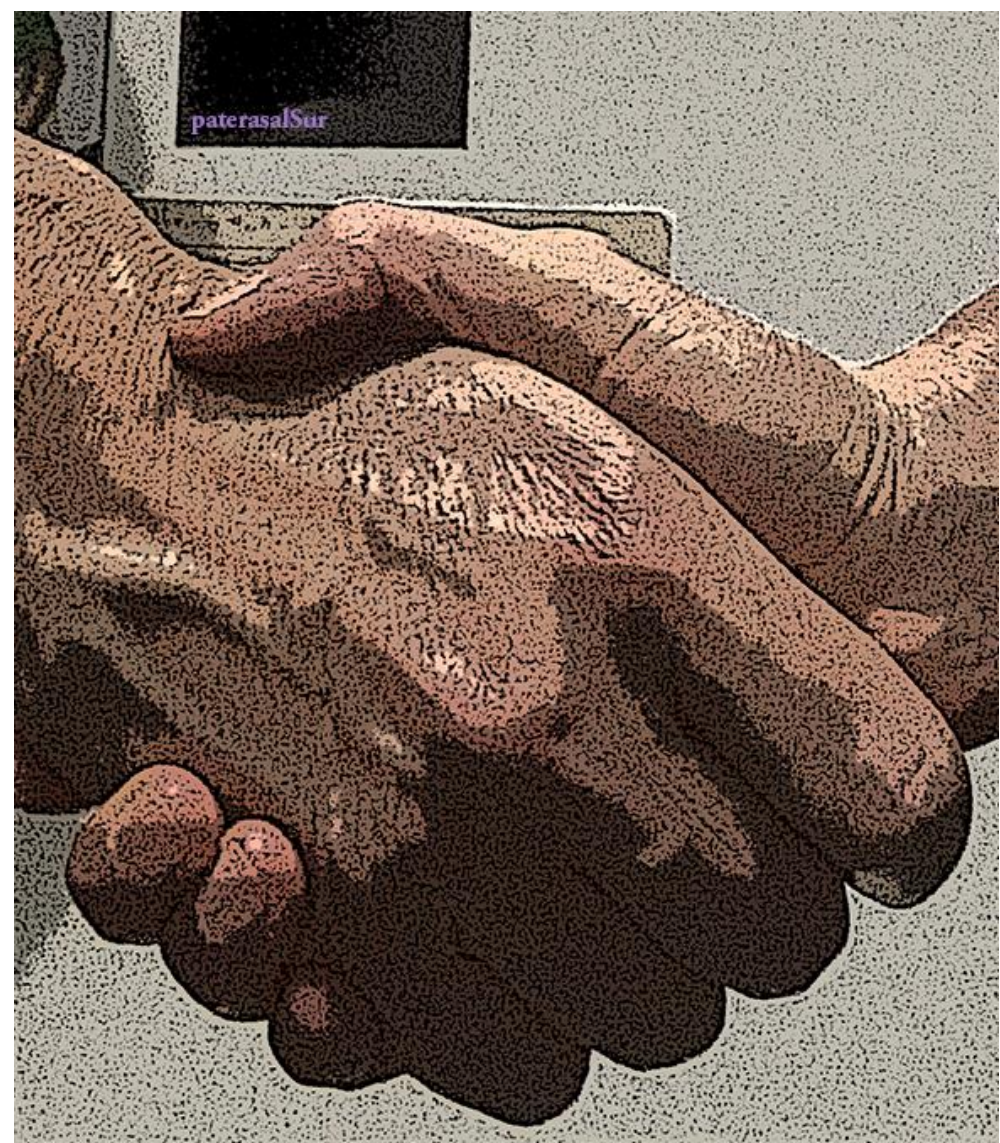

Composición y foto: Iñaki Chaves, 2020.

Por estos largos días, acaso ya demasiados, el entrañable y solidario abrazo, que rubricaba reencuentros y adioses, se ha quedado reducido a una escultura que lo representa, tal como nos quiso legar Genovés (figura 2) para resaltar el valor del compromiso las relaciones sociales en tiempos difíciles. Todo un símbolo de la reconciliación en el que un grupo de personas "se están mirando entre sí, sin importar sus rostros, los colores de su piel, la edad de sus arrugas, la tristeza o alegría de sus miradas o la religiosidad de sus creencias. Simplemente se abrazan, un gesto mayúsculo" (Chaves, 2020, 17 de mayo). 
Figura 2. El abrazo (2003), obra escultórica de Juan Genovés en Madrid

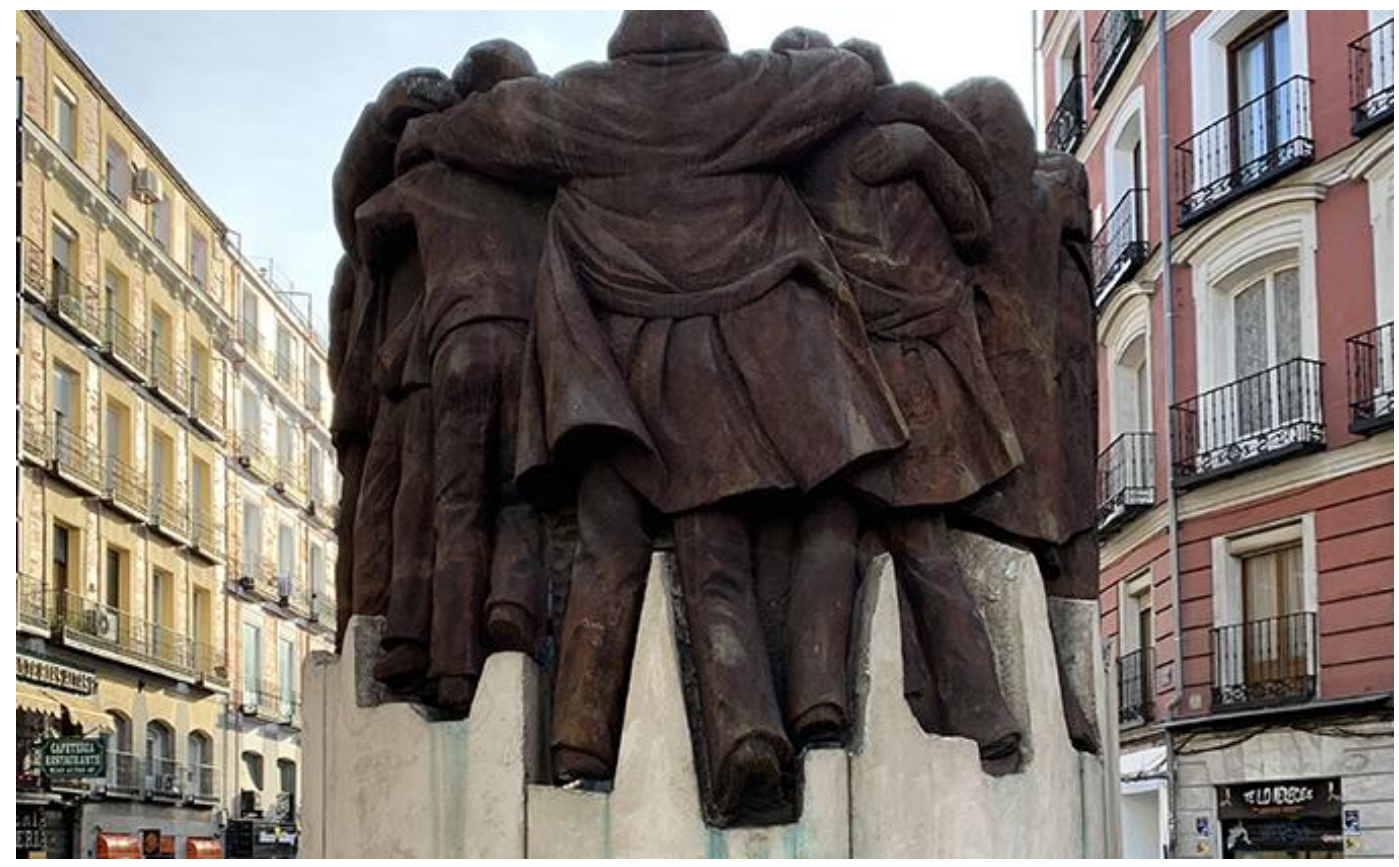

Foto: Iñaki Chaves (2019).

Las circunstancias sanitarias han hecho que los cariñosos y tiernos besos se hayan convertido en una plana representación bidimensional del roce de unos labios que besan, pero que ahora se atraen aunque no se tocan, como en la sublime obra maestra de Gustav Klimt (figura 3); en esta la gama de castos amarillos no permite la subida de tonos e impide los obscenos rojos que rodearían un ósculo más sexual. Una pintura de la que se dice que es una referencia al relato de Ovidio sobre la metamorfosis de Dafne, que es besada por Apolo antes de convertirse en laurel (Vives Chillida, 2013). Algo que "encaja" con estos momentos en los que el coronavirus está metamorfoseándolo todo. 
Figura 3. El beso, de Gustav Klimt (1907-08)

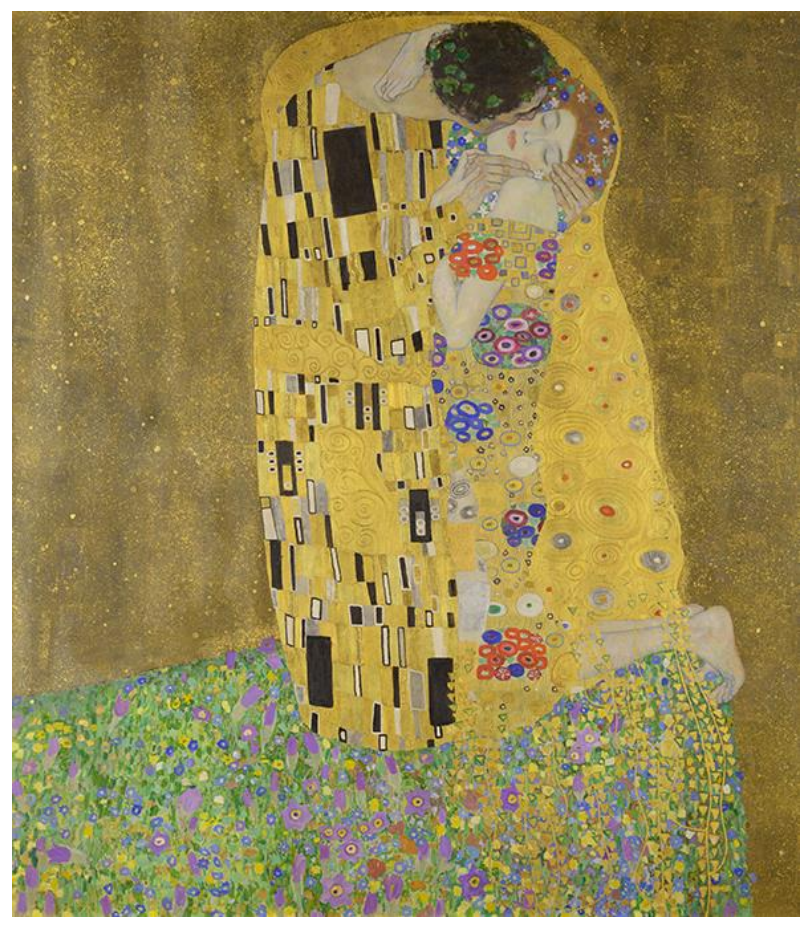

En este panorama, los cuerpos han pasado a ser, más que nunca, ese oscuro objeto de deseo, oprimido por las restricciones impuestas por el virus como la que imponía la sociedad burguesa de educación cristiana en la película de Buñuel (1977). En este caso, la meta inalcanzable se sitúa al otro lado de un cristal brillante que nos obnubila. Estamos continuamente, casi que minuto a minuto, frente al espejo, pero no hay comunicación social y mucho menos contacto. Lo que hay al otro lado no son las ilusiones de Alicia (Carroll, 2003), sino nuestros deseos y frustraciones, los anhelos de contacto y las conversaciones aparcadas con cuerpos que no sean nuestro propio cuerpo.

Somos retratos que quieren permanecer en el tiempo, colgado en cualquier sala de esta pinacoteca virtual en la que se ha convertido el espacio de la comunicación en la pandemia. Tal vez, en el fondo, estemos luchando por ser nosotros mismos y que nuestra imagen en la pantalla no se convierta 
en el retrato de Dorian Gray (Wilde, 2006), que el contacto con el arte virtual no nos borre de la realidad con su terror gótico.

Nos hemos vuelto adictos y adictas a las pantallas, aunque nos saturen, para poder comunicarnos y para vernos los cuerpos. Somos lo que el profesor Pérez Jiménez denomina “consumisos”, sumisos al y en el consumo de pantalla. Drogadictos enganchados al destello luminoso de un cuadro medido en pulgadas que se ha convertido, y más en tiempos de encierro y cuarentena sanitaria, en objeto cuasisagrado.

\section{Lienzos como conclusiones}

Esta será, mientras sigamos inmersos en la pandemia provocada por la covid-19, una reflexión abierta que tendremos que seguir alimentando y que no podremos cerrar hasta que dispongamos de más y mejores elementos de análisis para abordar esta especie de paradoja en la experiencia del tiempo.

Es por esto que la memoria precisa una alianza con el tiempo: su construcción no puede hacerse en el instante mismo de la experiencia sino cuando ella deviene pasado y el hacedor de memoria, el narrador, se sitúa en un punto en el que puede observar -o incluso crear- una causalidad que explique aquello que le ha sucedido. (Chaves et ál. 2020, p. 234)

Así tal vez podamos dar cuenta de una situación sin parangón, por la fuerza con que se ha producido y los efectos que está causando, y por lo mediático y global de su seguimiento. Tal vez en unos años retomemos la tarea y veamos, con la objetividad que dan la perspectiva y el tiempo, que fue una metamorfosis profunda que afectó el fondo de la sociedad, que golpeó a las clases más desfavorecidas, pero que, en la superficie todo, o casi, siguió funcionando igual. Todo cambió para que continuará igual. 
Entre tanto, más pinturas irán llenando los espacios del nuevo museo de nuestras relaciones sociales. Estaremos buscando, al otro lado del espejo, las alegrías que ya no tenemos, si es que alguna vez las llegamos a disfrutar, para poder sentir y sentirnos como antes de que todo esto pasara. Volviendo a tener la libertad de poder pecar para encontrarnos, si así lo deseamos, en nuestro propio jardín de las delicias entre tentaciones y deseos opacados por la pandemia (figura 4).

También anhelamos salir de nuestro encierro y conseguir la manumisión de nuestras vidas errantes y etéreas que vagan entre cuatro paredes, caminando del salón a la cocina y del baño al dormitorio, para terminar siempre frente a la pantalla, para encontrarnos finalmente con nuestras profundas locuras, con cuerpos, nuestros cuerpos, que se debaten entre la polarización y la conspiración, entre la infodemia y el desconocimiento, entre el contacto virtual y la incomunicación física. Hemos estado "conectados" sin estar realmente "comunicados", buscando "producir imágenes con cierto sentido para poder interpretar este nuevo mundo que habitamos desde la individualidad de la vida cotidiana" (Chaves et ál., 2020, p. 237). 
Figura 4. Primer cuadro de conclusión. El jardín de las delicias (1490-1500), pintura de El Bosco (detalle)

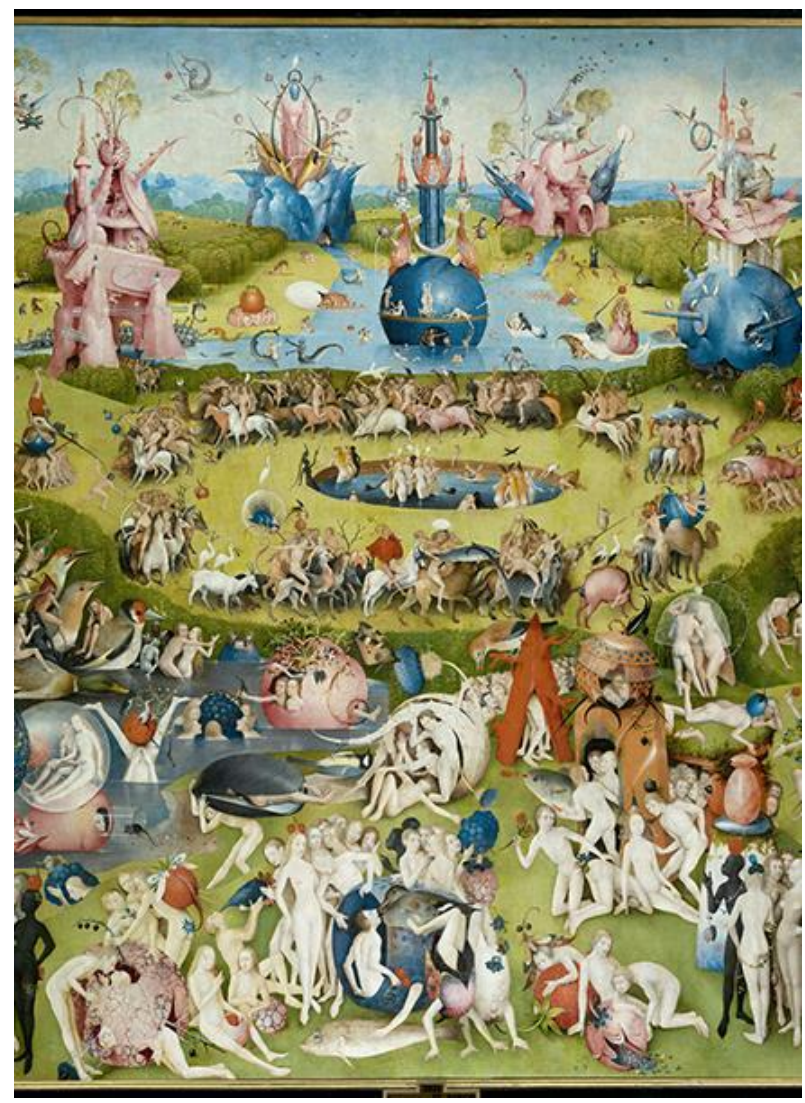

Hemos permanecido, quizás más tiempo del debido, navegando entre plataformas colaborativas y consultando páginas web para no llegar a saber si al final somos locos o somos necios, si vamos hacia la tierra de los insanos a con rumbo a la de la riqueza dejando a la vista en el camino las debilidades humanas (figura 5) (Foucault, 2018). 
Figura 5. Segundo cuadro de conclusión. La nave de los locos (1503-04), pintura de El Bosco

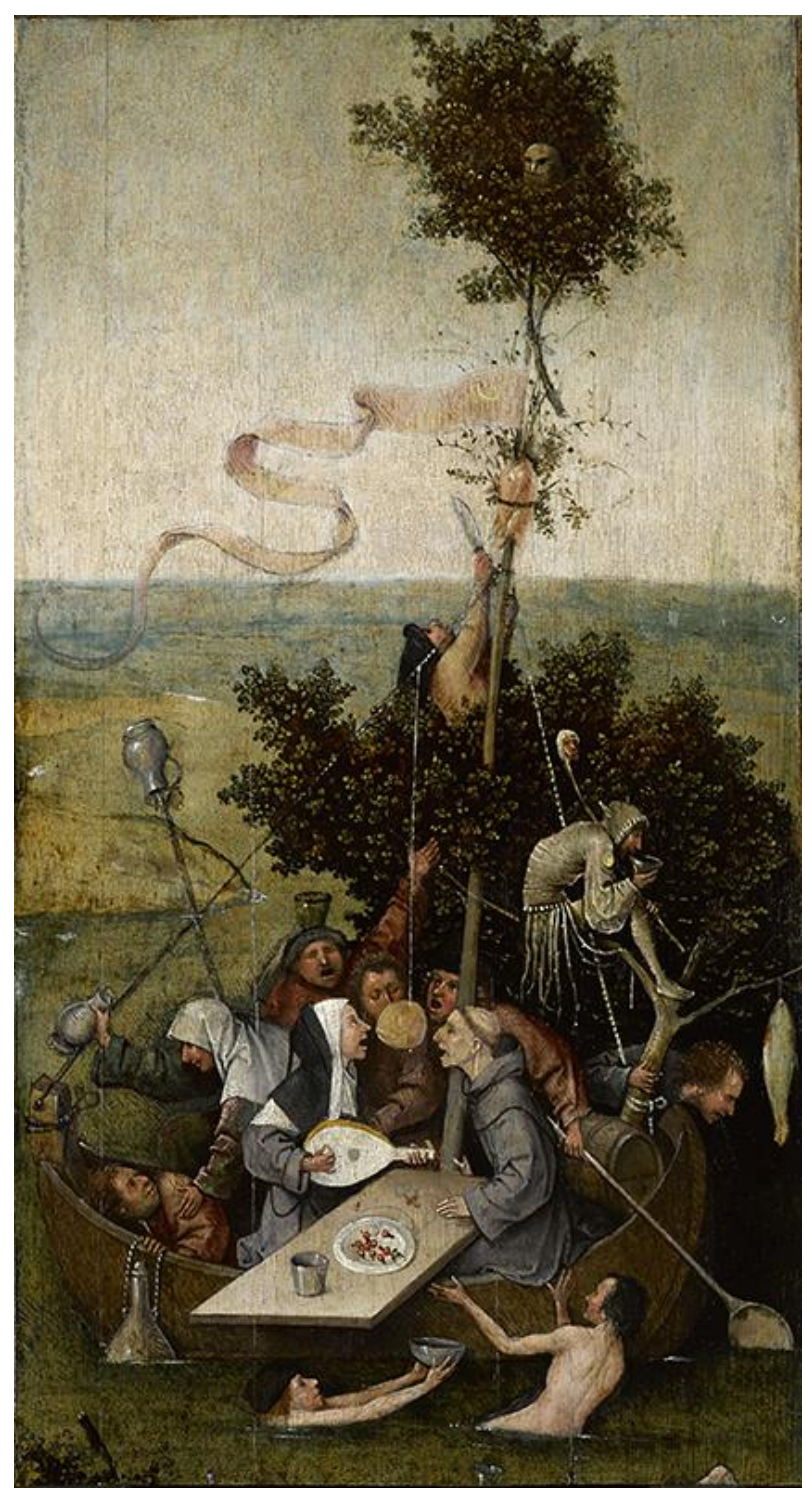

Entre los alegres colores de las antiguas certezas que nos hacían sentirnos vivos, comunicados y en contacto con la realidad, la de cada uno, ya fuera por el baile en pareja, por la música en soledad, por una lectura compartida, o por las miradas comprometidas, dentro de la oscura sala de un cine o acodados en la barra de cualquier cutre bar. 
Sabíamos que teníamos por delante toda la vida, por corta o larga que fuera. Una existencia en la que desfilan una por una y en lógica secuencia las etapas que vamos cumpliendo, como la mujer de "La danza de la vida" de Munch que está representada en su juventud, su madurez y su vejez (figura 6). Ahora nos sentimos tan desconcertadas que no sabemos qué etapas cumpliremos, pero seguimos aferrándonos a la vida.

Figura 6. Tercer cuadro de conclusión. La danza de la vida (1899-1900), pintura de Edward Munch

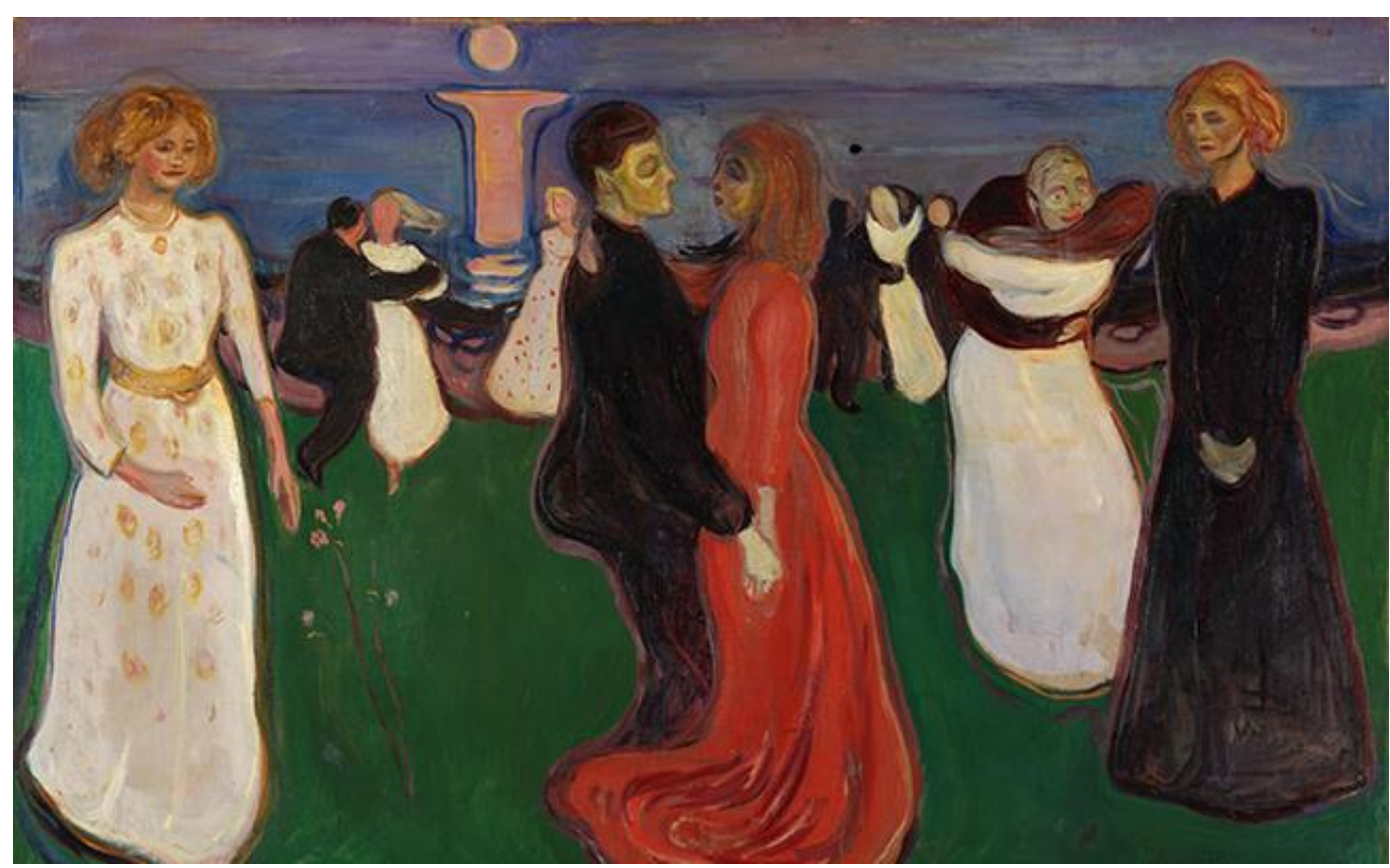

\section{Una pintura a modo de cierre}

En estos momentos cambiantes, se nos muestran frente a la mirada los colores ocres de las presentes incertidumbres, sin comunicación directa y en sociedad, sin contacto físico y con la sonrisa, o la mueca, oculta tras una máscarilla que no deja transmitir los gestos. Son instantes ya eternos en los que vamos viajando sin sentido del ser al estar; de la convivencia al aislamiento; del existir al desaparecer, y del pensar al gritar (figura 7). 
Figura 7. El grito (1893), pintura de Edward Munch

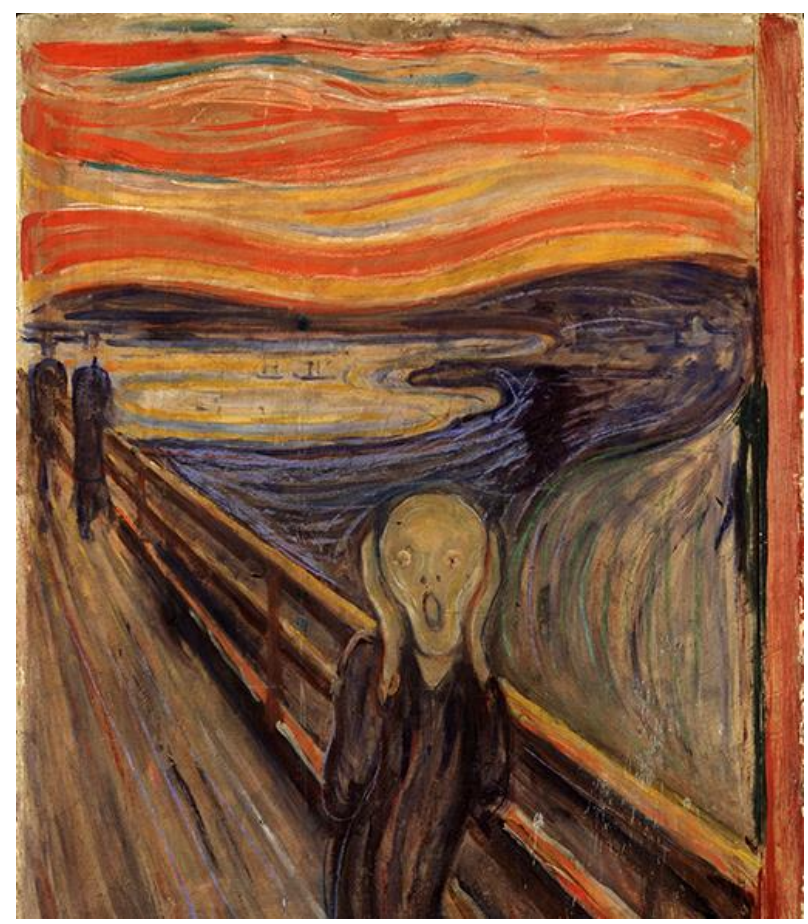

Estamos tan desesperados como el expresivo sujeto pintado por el artista noruego en otra de sus famosas obras. ¿Gritamos porque somos responsables de nuestra actual situación? ¿O estamos vociferando al vacío al constatar cómo nuestra acción sobre el planeta ha provocado la crisis que sufrimos?

Es nuestra incierta existencia, en la que hablamos sin mayores traumas de lienzos, de realidades, llenos de cifras, estadísticas y gráficas, como si esos números no representaran vidas. No solo las vidas que se está cobrando la pandemia, sino las que esta oculta con su mediática y omnímoda presencia.

Con ello estamos "normalizando" otras "anormalidades", como las violencias, la pérdida de derechos, las inequidades, el reparto de la pobreza, la explotación de recursos naturales y de seres humanos... Los 
cuerpos, los seres que los habitamos, hemos pasado a un segundo o tercer orden.

En la guerra contra el coronavirus están quedando en la cuneta las otras luchas, las de las gentes de abajo, las de quienes nunca cuentan, salvo que se conviertan en portada de noticieros por el drama que suponen. Está volviendo, si es que alguna vez se fue, la violencia extremista de la derecha más recalcitrante del continente. (Chaves, 2020, 16 de agosto)

Y de lo que nos damos cuenta es de que realmente hemos entrado en un nuevo cuadro del mundo, en una nueva era del ser humano sobre la faz de la Tierra. No será ya la del neoliberalismo, la del posconsumismo, ni siquiera la del Antropoceno. Una etapa en la que un virus ha dibujado una nueva pintura para toda la población y que nos ha hecho admitir lo que la mayoría definen como la "nueva normalidad", o la "nueva realidad", que en el fondo es aceptar lo inaceptable. Con el virus ha llegado la "nueva normalidad" y la pérdida de nuestra humanidad: "Recitamos cifras sobre infectados, recuperados y fallecidos por la pandemia, nos despreocupamos del dolor generalizado y asumimos contagios y muertes como parte de la 'nueva normalidad'. Debiéramos hacer un examen de conciencia, al menos" (Aharonian, 2020).

\section{Posible panorama pospandemia}

No se puede luchar por el pan (lucha económica) sin luchar por la paz (lucha política) y sin defender la libertad (lucha ideológica). POLITZER (2004) 
Nunca sabremos a ciencia cierta si la de ahora es otra realidad tan “anormal" como la de antes. Lo que sí podremos afirmar es que en algún momento será calificada como la era poscovid-19, la era de la plandemia. Una época en la que el arma más eficaz ha sido el temor a perder las seguridades y certezas que teníamos, los bienes que disfrutábamos, los servicios que pagábamos. La coacción y la extorsión provocadas, consciente o inconscientemente, por el miedo a un virus que existe pero que está rodeado de otros enemigos no tan visibles han sido aprovechadas para robarnos derechos y libertades (Martín, 2020).

Lo cierto es que tendremos que reivindicar el valor de la comunicación y del contacto, de las relaciones sociales en comunidad, para mantener la lucha y hacer frente a esa posverdad que nos invade y que pinta un cuadro lleno de

[...] un arsenal ideológico difícil de rebatir. Difícil porque la fuerza de los argumentos surge de un horizonte compartido de creencias y convicciones. Este horizonte no es en absoluto fijo, ni debería serlo, pero con la extrema polarización ideológica, por un lado, y la conspiranoia, por otro, está entrando en una dinámica autodestructiva. (Wagner, 2020)

La comunicación humana ha perdido la confianza, además, por el aislamiento corporal y social, por esa inundación de falsedades, temores e incertidumbres. Eso hace que se resienta la convivencia social que, pese a todos los embates que nos golpean, nos mantiene en cierta medida vivos y activos. Es un destacado recurso moral. Desempeña además una función epistémica crucial en cualquier acto de comunicación.

Son necesarios otros medios de comunicación que sustituyan o contrarresten los medios masivos de información, 
Los medios de comunicación convencionales son, sin duda, el medio más efectivo por el cual la visión liberal del mundo del individuo, de los mercados, del desarrollo, del crecimiento y del consumo se reproduce en la vida cotidiana. [...] Por consiguiente, el desarrollo de nuevos medios es clave para la creación de posibilidades diferentes para hacer mundos de otro modo. (Escobar, 2014, p. 152)

Las universidades también tendrán que asumir su papel en esta tarea de enfrentar la etapa pospandemia y aprovechar la crisis para tomar posición y

[...] pensar en una alternativa al modelo de sociedad y de civilización en el que hemos vivido, basada en una explotación sin precedentes de los recursos naturales que, junto con la inminente catástrofe ecológica, nos lanzará a un infierno de pandemias recurrentes. (Santos, 2020)

La universidad y sus profesionales deberán ser la punta de lanza para mantener viva la lucha de clases y la ideología. Nos han colonizado los cuerpos y han mercantilizado sus contactos, han concentrado en pocas manos el poder de la comunicación para mantener la desinformación. No queda otra que volver a las calles, luchar y "reXistir" (una mezcla consciente y sentipensante del resistir para existir de otra manera, mejor). Todo cambia, y así como lo hace el mundo también lo hacemos los seres humanos. Pero intentemos que ese cambio sea sin perder la idiosincrasia de la humanidad: la comunicación que nos relaciona y el contacto que nos roza con los otros, con los demás.

Habremos vivido, como antes y como nunca, una transformación profunda en nuestra manera de comunicarnos y en nuestra forma de contactarnos. Nuestra comunicación no será tan social y será condicionada por esa virtualidad impuesta de la que "podemos preguntarnos si cuando hagamos memoria de este tiempo será nuestra propia imagen en la pantalla, 
evocada en solitario y en silencio, la que mejor nos represente" (Chaves et ál., 2020, p. 239). Nuestros contactos ya no tendrán el mismo tacto.

Necesitaremos de una metamorfosis humana y social en la que, queramos o no, habremos de asumir que hemos cambiado, que la comunicación y el contacto se han transformado durante la pandemia. Ojalá que todos esos cambios no sean para que todo siga igual.

\section{Referencias}

Aharonian, A. (2020, 4 de septiembre). La 'nueva normalidad', el virus y nuestra pérdida de humanidad. América Latina en movimiento.

https://www.alainet.org/es/articulo/208792

Buñuel, L. (dir.). (1977). Ese oscuro objeto de deseo [película]. Greenwich Film Productions.

Chaparro, M. (2015). Claves para repensar los medios y el mundo que habitamos. Ediciones Desde Abajo.

Chaves, J. I. (2020, 16 de agosto). La otra pandemia. Pateras al Sur https://paterasalsur.wordpress.com/2020/08/16/la-otra-pandemia/

Chaves, J. I. (2020, 14 de junio). El encierro como una película. Pateras al Sur https://paterasalsur.wordpress.com/2020/06/14/el-encierro-como-una-pelicula/

Chaves, J. I. (2020, 17 de mayo). Anguita y Genovés. Pateras al Sur https://paterasalsur.wordpress.com/2020/05/17/anguita-y-genoves/

Chaves, J. I., Ruiz, G. y Múnera, B. (2020). La imagen y la construcción de la memoria de las realidades que habitamos durante la pandemia. En Hidalgo, T., Herrero, J. y Segarra, J. (coords.). (2020). Comunicación, periodismo y publicidad: retos profesionales en tiempos de crisis. Fragua.

Colorado, J. A. (2019). Hablar de fotografía es hablar de historia y de memoria. En Múnera, B. y Chaves, J. I. La fotografía, un documento social (pp. 99-106). Ediciones Desde Abajo. 
Escobar, A. (2014). Sentipensar con la tierra: nuevas lecturas sobre desarrollo, territorio y diferencia. Universidad Autónoma Latinoamericana.

http://biblioteca.clacso.edu.ar/Colombia/escposunaula/20170802050253/pdf 460.pdf

Foucault, M. (2018). Historia de la locura en la época clásica. Fondo de Cultura Económica.

García, L. (coord.). (2007). De la educación a distancia a la educación virtual. Ariel.

Martín, C. (2020). La verdad de la pandemia: quién ha sido y por qué. Martínez Roca.

Pérez Jiménez, J. C. (2020, 4 de septiembre). “Consumisos. El malestar en la cultura de las pantallas". Telos 113. https://telos.fundaciontelefonica.com/consumisos/

Politzer, G. (2004). Principios elementales y fundamentales de filosofía. Akal.

Santos, B. de S. (2020, 10 de julio). Coronavirus y educación: la universidad pospandémica. Página 12. https://www.pagina12.com.ar/277750-coronavirus-yeducacion-la-universidad-pospandemica

Vives Chillida, J. (2013). El significado iconográfico de El beso (los enamorados), de Gustav Klimt. International Art Nouveau Congress. Barcelona, junio de 2013. http://artnouveau.eu/admin ponencies/functions/upload/uploads/Julio Vives Chillida PaperB.pdf

Wagner, A. (2020, 8 de septiembre). La pandemia, una oportunidad para el periodismo responsable. The Conversation. https://theconversation.com/la-pandemia-unaoportunidad-para-el-periodismo-responsable-145704

Wilde, O. (2006). El retrato de Dorian Gray. Gredos. 